\title{
Jubiläumskongreß der Ungarischen Ophthalmologischen
}

\section{Gesellschaft}

D. Die Ungarísche Ophthalmologische Gesellschaft feierte mit der am 25. und 26. Mai d. J. in Budapest abgehaltenen Jahresversammlung das 25Jährige Jubiläum ihres Bestehens. Am Kongreß nahmen in gro-ßer Zahl Augenärzte aus alien Teilen des Landes teil, auch die ungarischen Ärzte der abgetrennten Gebiete waren vertreten. Der Vorsitzende Prof. Dr. /. v. Imre sen. schilderte in seiner Eröffnungsrede ausführ-lich die Entwicklung der ungarischen Augenheilkunde und bezeichnete die Wege, die sie in Zukunft einschlagen soil. Staatssekretär Prof. Dr. K. v. Scholtz begrüßte den Kongreß im Namen der Regierung; er ge-dachte mit pietätvollen Worten des Begründers der ungarischen Augenheilkunde, Wilhelm Schulek, zu dessen Schülern auch der Redner selbst gehörte. Er hob sodann die Verdienste der Gesellschaft um die Be-kämpfung der Blindheit und des Trachoms hervor. Der Sekretär der Gesellschaft Dr. Gustav Horay entwickelte in seinem Bericht die 25Jäh-rige Geschichte der Gesellschaft. Es wurden in dieser Zeit 16 Refe-raten-Vorträge (7 davon befaßten sich mit Trachom1, 4 SchulekGe-dachtnis-Vorträge (von: Prof. E. v. Gròsz, Prof. /. v. Imre sen., Prof. L. v. Blaskovics und Prof. /. v. Imre jun.) und 329 Vorträge, 275 Demon-strationen und 72 klinische Mitteilungen in den wissenschaftlichen Sitzungen gehalten, deren Referate in ungarischer Sprache und in zwei deutschen Fachschriften (Zeitschrift f. Augenheilkunde und Klin. Mo-natsblätter f. Augenheilk.) erschienen. Im August 1916 fand eine Kriegs-tagung unter Teilnahme deutscher, österreichischer, bulgarischer und türkischer Ophthalmologen statt. - Die Generalversammlung wählte sodann Prof. Van der Hoeve (Leiden) und Prof. E. v. Gròsz, den ersten Präsidenten der Gesellschaft, zu Ehrenmitgliedern der Ung. Ophth. Gesellschaft. Sodann folgten die Neuwahlen: Vorsitzender: Prof. L. v. Liebermann, zweiter Vorsitzender: Primarius G. v. Vajda (Miskolc), Sekretär: Assistent Dr. G. Horay. Nach der Generalversammlung fand die wissenschaftliche Tagung statt, die durch das hochbedeutsame Refe-rat von Prof. E. v. Gròsz und Primarius E. Lénárd über ,,Geographie und Prophylaxe des Trachoms” eingeleitet wurde. Auf dem Programm der Tagung standen außerdem 22 Vorträge, über die demnächst an dieser Stelle ein Referat berichten soil. 